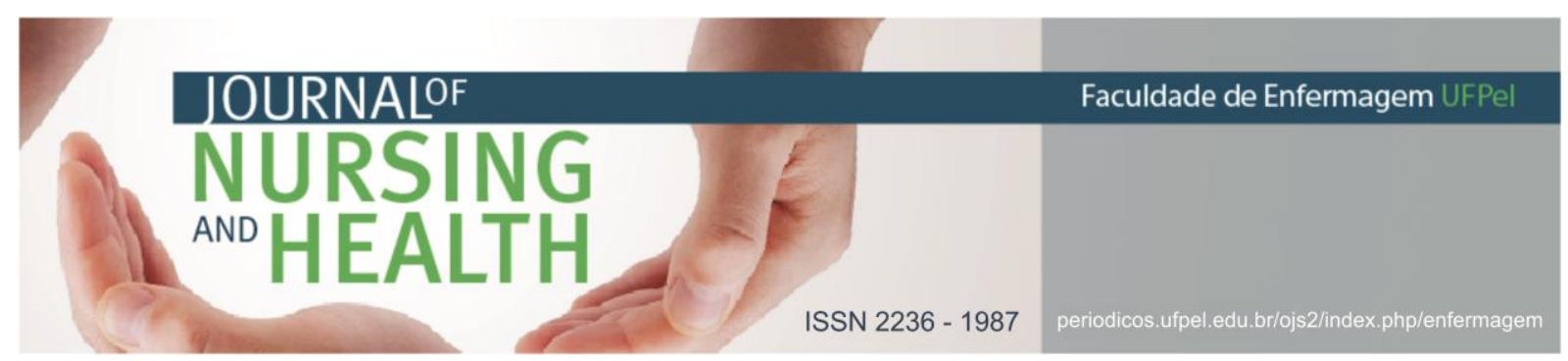

ARTIGO ORIGINAL

\title{
Reabilitação psicossocial de moradores de um serviço residencial terapêutico
}

\author{
Psychosocial rehabilitation of residents of a residential therapeutic service \\ Rehabilitación psicosocial de residentes de un servicio residencial terapéutico
}

Cortes, Helena Moraes ${ }^{1}$; Barros, Sônia ${ }^{2}$

\begin{abstract}
RESUMO
Objetivo: analisar o processo de reabilitação psicossocial no cotidiano dos moradores deste serviço. Métodos: trata-se de um estudo de caso, com abordagem qualitativa. 0 referencial teórico adotado foi a Teoria do Cotidiano e a Reabilitação Psicossocial. Utilizou-se como técnica de coleta de dados a observação participante. Foram sujeitos deste estudo, seis moradores de um serviço residencial terapêutico. Os dados foram analisados pela técnica de análise temática, considerando os aspectos históricos e sociais em que foram coletados. Resultados: evidenciaram a vida cotidiana, a alienação cotidiana e a superação desta alienação. Considerações finais: evidencia-se a reabilitação psicossocial quando os moradores se apropriaram de seus cotidianos, todavia, em alguns momentos os cotidianos ficaram alienados e utilizou-se mecanismos para superá-los. São necessárias estratégias constantes, para profissionais, a fim de tornar o morar/cotidiano destes moradores possível.
\end{abstract}

Descritores: Enfermagem psiquiátrica; Serviços de saúde mental; Desinstitucionalização.

\section{ABSTRACT}

Objective: to assess Psychosocial rehabilitation process and daily life of people residing in a Service. Methods: this is a case study with qualitative approach. Theoretical framework was the Theory of Daily life and Psychosocial Rehabilitation. Participant observation were used as data gathering method. Six residents of a Service were subjects of this investigation. Data were analyzed through the thematic analysis technique, considering the historical and social contexts in which data were gathered. Results: evidenced daily life, daily alienation and overcoming this alienation. Final considerations: psychosocial rehabilitation is evident when the residents have appropriated their daily lives, however, at times, the daily life has been alienated and mechanisms have been used to overcome them. Constant strategies are needed for professionals in order to make the living/daily life of these residents possible.

Descriptors: Psychiatric nursing; Mental health services; Deinstitutionalization.

\footnotetext{
${ }^{1}$ Enfermeira. Doutora em Ciências. Professora Assistente do Centro de Ciências da Saúde da Universidade Federal do Recôncavo da Bahia, Cruz da Almas, Brasil. E-mail: helena@ufrb.edu.br

2 Enfermeira. Doutora em Enfermagem. Professora Titular do Departamento de Enfermagem Materno Infantil e Psiquiátrica da Escola de Enfermagem da Universidade de São Paulo, São Paulo, Brasil. E-mail: sobarros@usp.br
} 


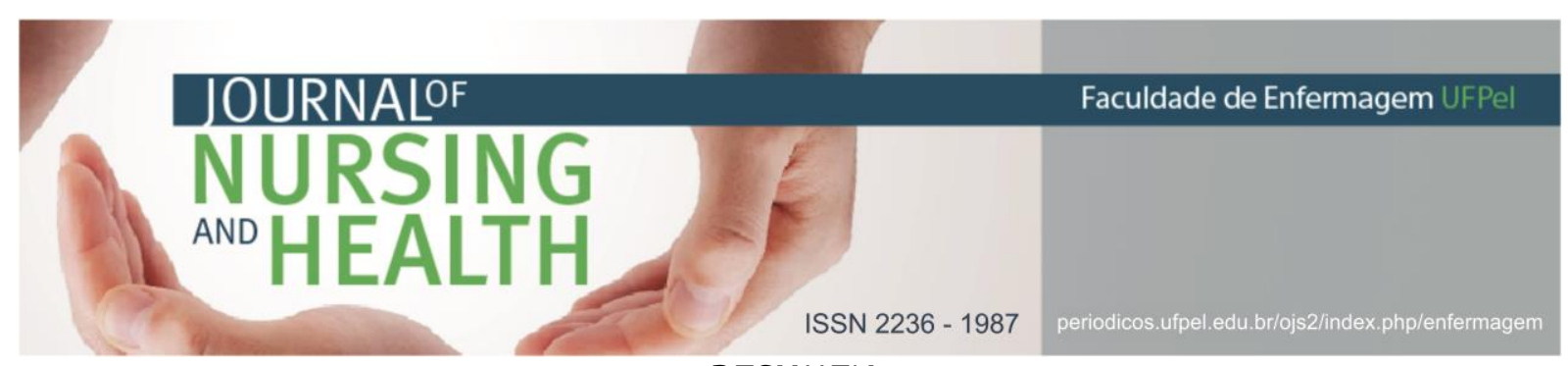

RESUMEN

Objetivo: se buscó analizar el proceso de rehabilitación psicosocial en el cotidiano de los moradores del servicio. Métodos: se trató de un estudio de caso, con abordaje cualitativa. El referencial teórico fue la Teoría del Cotidiano e la Rehabilitación Psicosocial. Se utilizó como técnica de recolección de datos la observación participante. Fueron sujetos de este estudio, seis moradores del servicio. Los datos fueron analizados mediante la técnica de análisis temática, considerando los aspectos históricos y sociales en que fueron recolectados. Resultados: evidenciaron la vida cotidiana, alienación cotidiana y la superación de esta alineación. Consideraciones finales: la rehabilitación psicosocial es evidenciada cuando los moradores se apropiaron de sus cotidianos, sin embargo, en algunos momentos los cotidianos se tornaron alienados, utilizando mecanismos para superarlos. Son necesarias estrategias constantes para profesionales con el fin de tornar el vivir/cotidiano posible en estos moradores.

Descriptores: Enfermería psiquiátrica; Servicios de salud mental; Servicios de salud mental.

\section{INTRODUÇÃO}

Serviços

Residenciais

Terapêuticos são moradias inseridas preferencialmente na comunidade, com a finalidade cuidar de pessoas que passaram longos anos asiladas em hospitais psiquiátricos. Do ponto de vista de estrutura social, é no desenvolvimento das habilidades cotidianas que o homem se firma enquanto ser social amadurecido. ${ }^{1} 0$ 'morar numa casa' é constituído por previstos e imprevistos, afetos e conflitos, organização e desorganização que permeiam o cotidiano de toda a pessoa.

Considera-se que a reabilitação psicossocial está intrinsecamente ligada ao eixo do morar, enfatizando a apropriação simbólica e material dos espaços, desenvolvendo o poder de contratualidade. Conforto, privacidade, segurança, apropriação do espaço e aumento do poder contratual no espaço da casa são vértices do cotidiano das pessoas, que podem ser indicativos qualitativos do próprio processo reabilitatório. ${ }^{1}$ Portanto, alinhamos nossa compreensão com os princípios da
Reabilitação Psicossocial, que entende que para incluir as pessoas no mundo da vida, necessariamente, precisamos emancipar o louco e seu modo diferente de existir. Escassos estudos têm tido a preocupação de investigar o cotidiano dos moradores, do ponto de vista de qualidade do morar, de como este cotidiano está estruturado numa perspectiva de sucesso. ${ }^{2-4}$ Entendemos a necessidade de uma maior compreensão de todos estes aspectos, a fim de entender a vida cotidiana de pessoas com doença mental e que moram num dispositivo-casa encravado na comunidade.

Um estudo discute o processo de trabalho de cuidadores de um Serviço Residencial Terapêutico (SRT) e suas ações compreendidas a partir das atitudes dos moradores. A reabilitação psicossocial e a retomada da vida cotidiana por parte dos moradores são constatadas a partir das ações dos profissionais, que possibilitaram a emancipação dos sujeitos. ${ }^{2}$ Todavia, este estudo não buscou compreender a reapropriação do cotidiano na perspectiva dos moradores, o que 


\section{IOURNALOF

consideramos primordial por serem eles os principais protagonistas de suas próprias vidas cotidianas. Verifica-se que os estudos tratam a temática das moradias comunitárias e seus moradores sob várias vertentes teóricas, entretanto, não trazem estes sujeitos e seus cotidianos para a centralidade de suas discussões, e é nesta perspectiva que este estudo se insere.

Portanto, quando pensamos na constituição histórica desse sujeito, enquanto peça central no processo de reabilitação psicossocial e que é ator principal de sua própria vida cotidiana, consideramos a necessidade de investigar a reabilitação psicossocial neste contexto das moradias comunitárias. Assim, questiona-se de que forma os moradores deste serviço apropriam-se de seu processo de morar/cotidiano. Objetiva-se, portanto, analisar o processo de reabilitação psicossocial dos moradores de um SRT.

\section{MATERIAIS E MÉTODOS}

Trata-se de um estudo de caso, realizado em um SRT do município de São Paulo (SP). O cenário foi um SRT do tipo I, localizado na região CentroOeste do município de SP. Este artigo é um recorte da tese de doutorado intitulada: "Lugar de morar: o cotidiano de pessoas com transtornos mentais de um serviço residencial terapêutico". Foram sujeitos desta investigação, seis moradores do SRT que aceitaram participar da pesquisa, e que estavam presentes no SRT durante o período de coleta de dados, ou seja, não estavam viajando ou em internação hospitalar; e que assinaram o Termo de Consentimento Livre e Esclarecido. Como este estudo buscou evidenciar os moradores do SRT como protagonistas de seus próprios cotidianos, os profissionais do SRT não foram incluídos. A coleta dos dados ocorreu de julho e agosto de 2014, de segunda a sexta-feira, totalizando 140 horas de observação participante.

Os dados foram coletados por meio do registro em diários de campo ("DC"), oriundos da técnica de observação participante. Foram atribuídos o código do “DC", seguido do número da localização da frase temática, referente a cada sujeito, garantindo-lhes o anonimato. Para o tratamento dos dados, adotou-se a técnica de análise de conteúdo temática, considerando-se os aspectos sociais e históricos do fenômeno social analisado. Desta forma, emergiu a seguinte categoria empírica: a vida cotidiana. Foi assumida a teoria do cotidiano e a categoria analítica da Reabilitação Psicossocial. ${ }^{1,3,5}$ Foram respeitados os princípios éticos em todas as etapas da pesquisa, de acordo com a Resolução $\mathrm{n}^{\circ}$ 466/2012 do Conselho Nacional de Saúde, do Ministério da Saúde. 6 projeto foi submetido e aprovado pelo Comitê de Ética e Pesquisa da Escola de Enfermagem da Universidade de São Paulo e pelo Comitê de Ética e Pesquisa da prefeitura municipal de São Paulo, sob CAAE: 29721114.5.0000.5392.

\section{RESULTADOS}

Os resultados deste estudo foram agrupados na categoria empírica denominada "a vida cotidiana", composta pelas subcategorias 
"alienação da vida cotidiana" e "superação da alienação da vida cotidiana".

\section{A vida cotidiana}

Esta categoria empírica permite conhecer a dinâmica da vida cotidiana dos moradores do SRT. A alienação da vida cotidiana destes moradores causada pelos longos anos de institucionalização no manicômio; os mecanismos encontrados por eles próprios ou então facilitados pela equipe de profissionais, para superar esta alienação e, algumas contradições, são evidenciados nas subcategorias a seguir.

\section{Alienação da vida cotidiana}

Os trechos dos diários de campo, a seguir, ilustram dificuldades que os moradores têm em romper um cotidiano hipertrofiado, ou ainda, contraditoriamente um cotidiano em que, os próprios profissionais dificultam que os moradores possam interromper mecanismos cristalizados ou cronificados. Esta hipertrofia ou alienação é compreendida como as consequências dos longos anos de institucionalização nos Hospitais Psiquiátricos (HP), traduzida na forma de estereotipados/cronificados, expressos a seguir:

Suj.6 é verificado todos os pertences das pessoas, pede para verificar minha mochila (do pesquisador) constantemente, pede tudo o que as pessoas portam o tempo todo, e isto é trabalhado com ele durante todo
- tempo na casa, pelos profissionais (DC2L74-77).

0 déficit no autocuidado e no cuidado com o meio que se encontra, traduz-se num "sintoma" de cronificação, que não foi abandonado, como fica expresso nos trechos:

Dona Suj. 1 corta legumes para o almoço, tem cabelos muito desarrumados, olhos estalados. Cuidadora diz que no próximo plantão irão cortar seu cabelo (DC1L57-59).

Suj.5 fuma no pequeno quintal e despreza o cigarro no chão, cuspindo logo em cima (DC1L5152).

$\mathrm{Na}$ sequência, é apresentado o comportamento infantilizado de uma moradora, brincando com bonecas, e tendo um quarto decorado como se fosse uma adolescente.

Este comportamento é reforçado pelos profissionais quando a tratam como uma criança, quando dizem ser a "tia” ou a "mãe", como fica evidente nos trechos dos diários de campo abaixo:

Suj. 5 antes de sair para consulta, tranca-se no banheiro e todos tentam convencê-la a abrir enquanto a coordenadora da casa passa outras instruções para dois dos cuidadores. Suj.4 tenta convencê-la a abrir a porta, dizendo a "tia" está aqui, após a cuidadora diz a mesma coisa. A cuidadora diz a "mãe" está aqui [...] (DC1L37-46). 
Suj. 5 passa grande parte da tarde fazendo desenhos e pintando álbuns infantis à mesa da sala e, depois caminha em círculos, no galpão por muito tempo, e a cuidadora incentiva este comportamento dizendo que ela é uma "mocinha" [...] Suj.5 sai vestida para a consulta médica de forma infantilizada (DC3L98100).

A subtração da vida cotidiana, em muitos momentos é, contraditoriamente, provocada pela equipe de profissionais, como no seguinte exemplo:

Toca o telefone até cair na sala da equipe [...] nenhum dos moradores atende na sala, pois os profissionais sempre atendem na sala de equipe (DC1L48-50).

A cuidadora explica que cada morador tem uma pasta no galpão, no armário onde é guardado todo o dinheiro, ficando em poder da equipe. Toda a movimentação é realizada como uma prestação de contas contidas num caderno (DC1L7174).

A cuidadora estende as roupas no varal e diz que em sua opinião apenas um morador teria habilidades que o permitisse viver sozinho numa casa, sem a presença de equipe (DC1.L75-79).

Todos aglomeram-se na frente do fogão, Suj.1, Suj.2, Suj.6, e Suj. 4 $e$ sentam-se a uma mesa na cozinha e dizem que é seu lugar de almoçar, enquanto isto, o cuidador chama a atenção dizendo que está cedo para almoçarem (11h30min) e o melhor é almoçarem meio dia em ponto, para não chegar em torno das 15 horas e, todos já estarem com fome, novamente (DC1L4347).

É dia de Suj.2 limpar o banheiro segundo a escala, entretanto, ele está resistente e a cuidadora me olha e diz sorrindo, olha só como eu faço a negociação, e diz para Suj.2 mostrando a chave, enquanto você não limpar o banheiro não tem passeio para você, e me diz que com Suj.2 é só assim a negociação, ou então, hoje não terá café enquanto, ele não cumprir as tarefas domésticas de sua escala (DC2L10-15).

Suj. 4 começa a relembrar que ontem as portas do CAPS foram fechadas por causa de Suj.6 e outro usuário que brigaram $e$ agitaram todo o CAPS, $e$ isto o lembrou o Hospital Psiquiátrico, na sua opinião (DC4L29-31).

A irmã de Suj.6 traz seu cartão magnético do banco, que este era o principal motivo de suas solicitações, e a profissional $Y$ do CAPS fala que ela estava bastante confusa e agressiva, e que quase não se via diferença nela e em Suj.6. [...] A profissional $Y$ insiste com Suj.6, que o cartão será entregue diretamente à Coordenadora do SRT para que ela possa comprar as vidraças por ele quebradas. Suj.6 diz que não entende esta lógica, pois se o 
cartão bancário é dele, precisa ficar com ele (DC6L5-16).

Suj. 1 fala que os acompanhantes terapêticos é que fazem as compras para a casa (DC1L91).

A cuidadora telefona, no meio da manhã, para saber se o pesquisador está na casa, dizendo estar preocupada, pois a casa "está sozinha", como diz Suj.4, ou seja, a cuidadora queria saber se o pesquisador estava na casa com os moradores (DC2L3-4).

Embora não existam profissionais de enfermagem trabalhando no SRT, as práticas asilares permeiam os processos de trabalho e foram nitidamente verificadas, como, por exemplo, nas situações cotidianas que seguem: a) o cuidador trata o morador de forma infantilizada; b) o cuidador atende o telefone do SRT (casa) a maior parte das vezes; c) o cuidador dispensa as medicações, em uma bandeja, d) no mesmo horário para todos os moradores; e) o cuidador serve as refeições para todos os moradores; f) o dinheiro dos moradores é controlado pelos profissionais por meio do registro no Livro "Pode"; g) o profissional cuidador tem a crença de que o morador é incapaz de morar sozinho; h) o profissional cuidador institui castigos, quando o morador recusa-se a realizar uma tarefa doméstica, a qual ele estava escalado; i) o profissional cuidador mantém as facas da casa em seu poder; o profissional do CAPS fecha, literalmente, as portas do serviço quando o morador entra em crise; j) o profissional do SRT mantém os pertences (cartão magnético bancário) do morador em seu poder, mesmo contra a vontade deste; l) o profissional cuidador considera a casa sozinha, se não houver profissionais nela, mesmo que haja moradores; $m$ ) o profissional cuidador não permite o acompanhamento do pesquisador nas consultas médicas na rede, mas permite 0 acompanhamento nas consultas com outros profissionais (terapeutas fisioterapeutas, ocupacionais, enfermeiros, dentistas).

\section{Superação da alienação da vida cotidiana}

Os seguintes trechos dos diários de campo mostram a não-interferência dos profissionais do SRT a todo momento na vida cotidiana dos moradores, contribui para o espontaneísmo e, desta forma, possibilita a superação da alienação cotidiana, como ficar parado à frente do fogão, esperando que o cuidador sirva as refeições.

o almoço transcorre normalmente e, pelo primeiro dia, hoje, ao final das 140 horas de observação, cada morador serve-se, diretamente nas panelas, sem a intervenção de nenhum cuidador (DC2L16-17).

A possibilidade de relacionar-se afetivamente, em um nível mais íntimo, possibilita que o morador rompa com a alienação cotidiana, cultuada no hospício, de que o louco não tem o direito de ter relações sexuais. Esta superação fica materializada nos trechos, a seguir: 
O cuidador $Z$ conta que em outros momentos, relações afetivas, em níveis mais íntimos, já ocorreram na casa, com um morador e com Suj.3, mas que esta relação foi caminhando por um lado "mais de amizade" com o tempo, e isto foi trabalhado pela equipe, de forma "natural", sem moralismo ou proibição, mas procurando preservar o morar e o cotidiano futuro deles mesmos na casa (DC2L69-73).

Chega a coordenadora meio-dia, e Suj. 4 conta que está feliz, pois um antigo namorado ligou, e a coordenadora incentiva que Suj. 4 a conseguir um trabalho, ou voltar a estudar, pois se ela quer constituir uma família (DC2L2729).

Ter a possibilidade de estudar e qualificar-se para 0 mundo do trabalho, alavanca o morador no seu cotidiano.

Suj. 4 mostra um "diploma" que logrou numa instituição de cunho religioso, de um curso de oficina e escrita (DC3L35-36).

A vida cotidiana dos moradores é permeada de fatos que objetivam o cotidiano, ou seja, que possibilitam ao sujeito morador ocupar / assimilar / apossar-se da sua casa. Noutras situações, o cotidiano ainda está alienado, induzido pelos profissionais do SRT. Contraditoriamente, estes mesmos profissionais possibilitam aos moradores, estratégias para a superação desta alienação cotidiana.

\section{DISCUSSÃO}

É necessário discutirmos a alienação da vida cotidiana, que se explicita na vida desses moradores, pelas consequências de anos de internação psiquiátrica, e na contradição da indução a esta cristalização de comportamento no cotidiano dos moradores, pelos profissionais do serviço (SRT).

A alienação aqui é compreendida de forma concreta, e fica materializada nos comportamentos hipertrofiados, cristalizados, cronificados que podem aprisionar o morador em seu próprio cotidiano, sem consciência de si mesmo e de seu entorno. Numa concepção helleriana, a alienação da vida cotidiana pode ser verificada quando as relações sociais impedem ou rompem a relação do indivíduo com as objetivações cotidianas, traduzindo-se em comportamentos poucos flexíveis. ${ }^{3}$ No campo da saúde mental, é possível que a vida cotidiana dos usuários se torne muito empobrecida, quando o indivíduo cumpre regras que the são impostas, de forma engessada e inflexível, sem consciência, alienandose. ${ }^{3-4}$ Neste estudo, verifica-se que as profundas marcas deixadas nos moradores pelos longos anos em que "estavam" no hospício, podem ser traduzidas por inúmeros comportamentos estereotipados, dependência dos profissionais para conduzir seu dia a dia e falta de iniciativa para gerenciar aspectos de sua vida cotidiana.

As materializações destas marcas puderam ser constatadas nos trechos discursivos apresentados, quando 


\section{JOURNALOF \\ NURSING \\ MOHEALTH}

ISSN $2236-1987$

que a institucionalização deixou nos pacientes internados nos Hospitais Psiquiátricos (HP) do país. ${ }^{9}$

As causas de internação em um $\mathrm{HP}$, são apontadas pelos autores como "histórias criminais" pelos autores, tatuagens pelo corpo associadas ao comportamento da pessoa, onanismo (masturbação), pederastia (homossexualidade masculina) ou ardor sexual. Todos estes motivos de internação psiquiátrica imprimiram nos sujeitos marcas para uma vida inteira, excluindo-os socialmente e os estigmatizando, impulsionando-os a uma vida cotidiana alienada. ${ }^{10}$

Algumas autoras apontam que o estigma e o preconceito com o doente e com a doença mental são construídos culturalmente e da mesma forma precisam ser desconstruídos. Evidenciam ainda, que essa hipertrofia no cotidiano - o estigma - dificulta as ações que poderiam incluir socialmente as pessoas com doença mental. ${ }^{11}$

Chama a atenção uma contradição dialética verificada neste estudo. 0 processo de trabalho alienado dos cuidadores induz a um cotidiano coisificado dos moradores. ${ }^{3}$ Se por um lado, o processo de trabalho dos profissionais do SRT ajuda o morador a objetivar o seu cotidiano e até mesmo superar a alienação deste, por outro lado, em outros momentos, este processo de trabalho subtrai o cotidiano do morador, alienando-o. Esta subtração foi constatada quando os profissionais executam as tarefas diárias "pelos" moradores e não "com" os moradores. Também foi possível verificar que o cotidiano dos moradores ficou alienado quando os 
profissionais os tratavam de forma infantilizada, ou ainda, quando demonstraram ter a crença de que o morador seria incapaz de morar sozinho ou desempenhar tarefas diárias na casa.

As práticas manicomiais / asilares configuram-se como instrumentos do processo de trabalho alienado dos profissionais do SRT e, que em muitos momentos, neste estudo, são responsáveis pela hipertrofia do cotidiano dos moradores, alienandoos. O cotidiano que sofre a ação de uma prática alienada, consequentemente, torna-se alienado. $^{3}$

Em relação ao processo de trabalho alienado no SRT - mesmo que apenas em alguns momentos - verificase uma contradição, pois as práticas asilares, a título de práticas de cuidado, são desempenhadas por cuidadores que sequer tiveram contato com a enfermagem em sua formação profissional. Tal formação resumiu-se a algumas reuniões entre todos os cuidadores da rede, de forma breve e pontual. Cabe dizer que, houve uma opção da gestão em não compor com profissionais de enfermagem na equipe para trabalhar no SRT, desde seu início de funcionamento, justamente para tentar se evitar que esses profissionais não reproduzissem aquelas práticas asilares institucionalizadas.

Estas contradições confirmam as convicções de outro estudo, quando afirmou que 0 entendimento do processo saúde-doença-mental é determinado culturalmente, estando circunscrita social e historicamente. É atestado pelo senso comum, reproduzindo-se nas teias sociais e relacionais em que os indivíduos se encontram inseridos. ${ }^{12}$

Sabe-se que o cuidado é finalidade específica, mas não exclusiva da Enfermagem, e considerando-se que também é ensinado culturalmente, mesmo no senso comum, é que se precisa ter a compreensão da origem da sua construção em saúde mental, pela óptica histórica. Uma pesquisa relembrou que o trabalho da Enfermagem psiquiátrica nasceu dentro do próprio hospício. E durante o século XIX, os cursos que ensinavam Enfermagem Psiquiátrica e de Saúde Mental não adotavam o sistema nightingaleano e eram conduzidos, quase que exclusivamente, por profissionais médicos. 0 processo de trabalho dos enfermeiros psiquiátricos acompanhou, portanto, o processo de medicalização do hospício. ${ }^{13}$

Entendemos, portanto, que essas práticas asilares foram transmitidas e aprendidas culturalmente, de modo a se reproduzirem hoje no contexto do SRT, mesmo sem a presença de profissionais de Enfermagem em seu quadro de profissionais. Desta maneira, compreendemos que, possibilitar a construção de uma vida cotidiana não alienada, independe de o SRT conter ou não esta ou aquela categoria profissional; o que interessa sim, é que as pessoas que lá estejam trabalhando, tenham destruído em si as amarras manicomiais, culturalmente instituídas. É destruindo as amarras manicomiais internalizadas que os profissionais compreendem que a vida cotidiana é a esfera da cotidianidade que mais tem propensão a ser alienada, entretanto, que não 


\section{JOURNALF

precisa ser alienada. A superação da alienação da vida cotidiana se dá na dimensão da superação da sociedade capitalista. A autora diz ainda que a superação da alienação da vida cotidiana é parte da construção de uma sociedade socialista, e a superação da alienação é possível e necessária. ${ }^{3}$

Entendemos que, a superação da alienação da vida cotidiana encontra convergência com os princípios da reabilitação psicossocial ao buscar romper com comportamentos cristalizados e a partir daí, possibilitar o impulso do sujeito com doença mental para inserir-se ao meio social. Embora na maior parte do tempo observado, a vida cotidiana dos moradores apresentou-se alienada, ou pelas profundas marcas deixadas pelas internações psiquiátricas, ou ainda, pela práticas asilares reforçadas pelos profissionais do SRT, sendo identificados alguns escassos mecanismos para a superação dessa alienação.

Esses mecanismos são construídos pelos próprios moradores, ou contraditoriamente, facilitados pelos profissionais do SRT, a saber: a) a nãointerferência dos profissionais, a todo instante, no cotidiano dos moradores, facilita 0 desenvolvimento das características cotidianas como espontaneísmo, pragmatismo e hierarquia; b) o morador ter a possibilidade de relacionar-se intimamente, com outra pessoa que pode ser morador ou não, dentro de sua casa (SRT) ou fora dela; c) ter meios financeiros para subsidiar-se e relacionar-se com o mundo concreto (poder de compra) como a aposentadoria; c) ter a possibilidade de manter o próprio dinheiro em seu poder e controlar seus gastos pessoais; d) ter a possibilidade de estudar como um direito de todo cidadão; e) ter a possibilidade de qualificar-se pessoalmente e inserir-se no mundo do trabalho.

Verificamos que a nãointerferência dos cuidadores de forma rotineira, constante e sistemática no cotidiano dos moradores, possibilita que os mesmos tomem a iniciativa, espontaneamente para realizar algumas tarefas, como por exemplo, servirem-se nas horas das refeições, sem ficarem aglomerados em frente ao fogão, esperando que o cuidador os sirva. O simples fato, de os moradores poderem servir-se à mesa, sem a presença do cuidador, de tomarem a iniciativa de fazer uma comida diferente no domingo, ou ainda, atenderem o telefone sem que alguém o faça por eles, permite que a vida cotidiana dessas pessoas possa ser permeada de momentos de espontaneísmo, por tomarem a iniciativa; de pragmatismo, por tornarem-se dinâmicos e considerarem que há outras atividades a serem realizadas em seu cotidiano; e de hierarquia, por entenderem que naquele momento é aquilo que precisa ser feito em detrimento de outra atividade ou não.

o espontaneísmo é a característica cotidiana em que a pessoa age no ato para satisfazer a sua vontade, sem racionalizar. 0 pragmatismo refere-se à agilidade em executar uma ação também sem pensar, num primeiro momento, porque a prática já ensinou ao sujeito 


\section{JOURNAIOF

que a ação resulta numa reação desejada ou não. 0 cotidiano é hierárquico, pois não se pode fazer tudo ao mesmo tempo, logo, a pessoa determina o que fará, de acordo com uma escala de valores que ela atribui. ${ }^{14}$ Realizar a maior parte das tarefas pelos moradores pode ser, num primeiro momento mais fácil para o profissional cuidador, pois desta forma, não terá que lidar com situações inusitadas, como mediar conflitos ou então, ajudar o morador a pensar estratégias para resolver outros problemas domésticos. Todavia, este é um cuidado que tutela, aprisiona e aliena o sujeito em seu próprio cotidiano.

Superar esta alienação implica em arriscar, em tentar fazer sozinho ou com o outro colega morador, esta ou aquela atividade; procurar resolver problemas que surjam naquela hora; expor-se; reconhecer seus limites e recorrer ao cuidador se necessário, em algum momento. Permitir que o morador vivencie a experiência de errar e acertar no cotidiano, é dar-lhe o direito mais óbvio e concreto de viver o cotidiano, que lhe foi subtraído nos anos internado no asilo.

Um estudo mostrou que, desde o século passado, na maior parte do mundo, as críticas ao modelo asilar como detentor do saber psiquiátrico, exclusivamente, já não têm mais razão de ser. 0 campo da saúde mental tem procurado, por intermédio de saberes e práticas do âmbito psicossocial, conceber o louco como um cidadão de direitos, e proporcionar-lhe um cuidado que o torne cada vez mais autônomo e empoderado de si mesmo, tendo a cidadania como eixo norteador. 0 cuidado proporcionado ao louco precisa ser pautado na premissa de que a loucura é uma questão da existência do cidadão em sofrimento. ${ }^{15}$ Em relação ao cuidado de pessoas com transtorno mental - moradoras de dispositivos comunitários - os estudos internacionais têm se inclinado para as boas práticas em saúde mental comunitária. Outro estudo realizado em Nova lorque, mostrou que, inclusive pessoas em situação de rua, quando são acolhidas e cuidadas de forma a privilegiar sua autonomia no cotidiano, conseguem apropriar-se de suas casas e as habitarem. ${ }^{16-17}$

Em relação ao cuidado de pessoas com doença mental no cotidiano, é indicado que os profissionais precisam desenvolver métodos que estimulem a autonomia, diminuam o estigma e a discriminação das pessoas; utilizem e desenvolvam métodos para avaliar a satisfação dos moradores, para que possam juntos tomar decisões de forma compartilhada e ofereçam um cuidado de fácil acesso para que o morador e seus familiares sintam-se aceitos. ${ }^{16}$ Além do cuidado com o cotidiano do morador-cidadão para preservá-lo de forma autônoma, os profissionais do SRT referem que é possível que os moradores se relacionem intimamente na casa, fora dela ou entre si, inclusive.

Alinhando o raciocínio com a perspectiva da Reabilitação Psicossocial, acreditamos que a possibilidade de se relacionar intimamente pode ser considerada um mecanismo de superação da alienação do cotidiano, facilitado pelos profissionais do SRT. Observou-se também que dois moradores estavam 


\section{JOURNALOF \\ NURSING \\ ANO HEALTH}

ISSN 2236 - 1987

utilização do dinheiro que também fica em poder dos profissionais.

Noutro estudo, num SRT do Sul do Brasil, foi verificado que o dinheiro dos moradores também era mantido em poder da equipe e, naquele serviço, adotavam a estratégia denominada Banco Pedagógico ${ }^{20}$, que é similar aos registros de controle do Livro-Pode. ${ }^{19-}$ ${ }^{20}$ Compreendemos que, independe da estratégia que o serviço adote para auxiliar o morador a controlar seus gastos, ter um rendimento que lhe permita subsidiar-se, que the dê poder de compra no território que habite seja proveniente dos benefícios estatais ou não - pode ser um mecanismo concreto para a superação da alienação da vida cotidiana.

Além do direito de receber os recursos financeiros estatais, como o benefício de Volta para Casa (auxílioreabilitação psicossocial, instituído pela lei $n^{\circ} 10.708 / 2003$ ), um morador aponta que teve a possibilidade de estudar e tem vontade de qualificar-se para ingressar no mundo do trabalho.

O trabalho é uma categoria importante para Heller, pois o trabalho é a manipulação da natureza pelo homem, objetivando-a, e produzindo algo com valor de uso e de troca. ${ }^{3} 0$ pensamento cotidiano compreende 0 trabalho também como gasto ou consumo, que entende-se estar ligado ao desgaste mental e físico do trabalhador, ao produzir algo com valor de uso. ${ }^{14} \mathrm{~A}$ categoria trabalho precisa ser entendida como um direito dos pacientes psiquiátricos e, como conquista de cidadania quando diz que o trabalho daqueles em cooperativas sociais, não é compreendido apenas como uma forma de dar respostas as 


\section{JOURNAIOF

suas necessidades, mas sim, de integrá-los ao mundo do trabalho como sócios e empreendedores, correndo todos os riscos que as negociações impõem. As cooperativas sociais de trabalho são recomendadas como uma alternativa para as pessoas em situação de vulnerabilidade social, pois permitem uma maior desvinculação do mercado de trabalho. ${ }^{1}$

No contexto da reabilitação psicossocial, publicações nacionais e internacionais têm mostrado experiências exitosas de trabalho como um direito de usuários de serviços de saúde mental. 11,21-22 Embora, nenhum morador esteja inserido no mercado de trabalho, uma moradora referiu ter tido a possibilidade de realizar um curso para qualificar-se e desejava ter um trabalho. Entendemos que essas duas possibilidades se constituem como mecanismos de superação da alienação cotidiana. Pois é por meio do trabalho, que o sujeito se (re)coloca no mundo, trocando a identidade de louco incapaz, pela de trabalhador. 1,21 Frisamos que, a superação da alienação cotidiana pelo trabalho precisa ser compreendida no contexto do trabalho protegido que, produz algo com valor de troca, seja por meio das oficinas de geração e renda e/ou por meio das cooperativas sociais.

Neste estudo, não negamos os aspectos subjetivos da vida cotidiana, mas optamos por analisá-la nos moradores do SRT, considerando os aspectos concretos, materiais, ou seja, as objetivações que envolvem este cotidiano, e que se desenrolam num meio social e historicamente construído. Embora os moradores deste SRT objetivem concretamente os seus cotidianos, ainda existem muitas dificuldades, sejam elas relacionais; pragmáticas (como ir pagar uma conta); hierárquicas (como decidir o que fazer primeiro); ou mesmo quando contraditoriamente, o cotidiano é induzido à alienação pelos próprios profissionais deste serviço. Morar num lugar protegido, para estas pessoas que carregam em si os precedentes manicomiais, precisa significar ter o direito da (re)construção de uma vida cotidiana alicerçada no princípio de cidadania, que é preocupação central da Reabilitação Psicossocial.

\section{CONSIDERAÇÕES FINAIS}

Cabe dizer que, algumas marcas deixadas pelo manicômio são traduzidas na forma de comportamentos cristalizados ou cronificados dos moradores, mesmo sem a indução dos profissionais do SRT. Algumas delas parecem ter acompanhado os moradores deste 0 Hospital Psiquiátrico e outras eram reforçadas pelos profissionais do SRT. Enfatiza-se que o fato da gestão ter optado por não contratar profissionais de Enfermagem para compor o quadro de profissionais do SRT, que foi cenário deste estudo - a fim de proteger os moradores das práticas asilares tradicionalmente instituídas que pudessem ser a eles dispensadas por tais profissionais - não afastou o senso comum predominante na sociedade sobre o louco e a loucura. Compreendemos que é importante que os profissionais que trabalham nos SRTs tenham desconstruído em si os precedentes manicomiais que são socialmente e historicamente ensinados. Neste sentido, sugere-se 


\section{NURSING \\ AND}

capacitações periódicas e oficinas técnicas de sensibilização aos trabalhadores, que atuam nesse serviço.

A ideologia manicomial, dominante em nosso meio social, é a força motriz que alimenta e retroalimenta essas práticas asilares, internalizadas e dispensadas pelos profissionais do SRT. Assumimos claramente, uma postura ética, estética e política da contraideologia balizada pela Reforma Psiquiátrica Brasileira, que entende o sujeito como um cidadão de direitos. Defendemos ainda, que as moradias protegidas, são um direito das pessoas que carregam em si, os precedentes oriundos das instituições psiquiátricas, que são as responsáveis por esses processos de alienação cotidiana.

A não-interferência dos profissionais nas atividades de vida diária cotidiana em todos os momentos do dia a dia, possibilitou um cotidiano mais pragmático, heterogêneo, espontâneo. Habitar, concretamente, uma casa implica em gastos financeiros. Ter meios financeiros para subsidiar-se contribui para superar a alienação cotidiana, pois reposiciona o sujeito no meio social, estabelecendo poder de compra, de troca concreta no meio social capitalista. Urge uma política pública que regulamente, rigorosamente, o direito à moradia e os benefícios devidos aos pacientes egressos de longas internações psiquiátricas e/ou que tenham uma doença mental grave, severa e persistente que, porventura, impossibilite-os para o trabalho.
ISSN 2236 - 1987

\section{AGRADECIMENTO}

Agradecimento à CAPES - pela bolsa de doutorado que deu origem a esta pesquisa.

\section{REFERÊNCIAS}

1. Saraceno B. Libertando identidades: da reabilitação psicossocial à cidadania possível. $2^{\mathrm{a}}$ ed. Rio de Janeiro: Te Corá/Instituto Franco Basaglia; 2001.

2. Sprioli N, Costa MCS. Cuidar em novo tempo: o trabalho de cuidadores com pacientes psiquiátricos em moradias. Rev latino-am enfermagem [Internet]. 2011 [acesso em 2017 fev 10];19(5):1155-62. Disponível em: http: / /www.scielo.br/ pdf/rlae/v19n5/pt_13.pdf

3. Heller A. 0 cotidiano e a história. $6^{\mathrm{a}}$ ed. São Paulo: Paz e Terra; 2000.

4. Salles MM. Vida cotidiana de usuários de CAPS: a (in)visibilidade no território [tese]. São Paulo (SP): Universidade de São Paulo; 2011.

5. Minayo MCS. 0 desafio do conhecimento. $12^{\mathrm{a}}$ ed. São Paulo: Editora Hucitec; 2010.

6. Ministério da Saúde (BR). Conselho Nacional de Saúde. Resolução 466 de 12 de dezembro de 2012: diretrizes e normas regulamentadoras sobre pesquisa envolvendo seres humanos. Brasília; 2012.

7. Borges VT. Um "depósito de gente": as marcas do sofrimento e as transformações no antigo Hospital Colônia Sant'Ana e na assistência psiquiátrica em Santa Catarina, 19701996. Hist cienc saude-manguinhos [Internet]. 2013 [acesso em 2017 maio 15];20(4):1531-49. Disponível em: 


\section{JOURNALOF \\ NURSING \\ AND 는}

ISSN 2236 - 1987

http: / /www.scielo.br/scielo.php?scrip $\mathrm{t}=\mathrm{sci}$ arttext\&pid=S0104-

$59702013000401531 \& \operatorname{lng}=e n$

8. Barroso SM, Silva MA. Reforma Psiquiátrica Brasileira: o caminho da desinstitucionalização pelo olhar da historiografia. Rev SPAGESP [Internet]. 2011 [acesso em 2017 maio 15];12(1):66-78. Disponível em: http: / / pepsic. bvsalud.org/scielo.php? script=sci_arttext\&pid=S1677-

$29702011000100008 \& \operatorname{lng}=p t$

9. Pitta AMF. Um balanço da reforma psiquiátrica brasileira: instituição, atores e políticas. Cienc saude colet [Internet]. 2011 [acesso em 2017 jan 11];16(12):4579-89. Disponível em: http: / /www.redalyc.org/articulo.oa?i $\mathrm{d}=63020981002$

10. Carrion CTP, Margotto LR, Aragão EMA. As causas das internações no Hospital Adauto Botelho (Cariacica, ES) na segunda metade do século $X X$. Hist cienc saude-manguinhos [Internet]. 2014 [acesso em 2017 maio 11];21(4):1323-40. Disponível em: http: / /www.scielo.br/scielo.php?scrip $\mathrm{t}=\mathrm{sci}$ arttext\&pid=S0104-

$59702014000401323 \& \operatorname{lng}=e n$

11. Salles MM, Barros S. Da cidadania à realização de projetos de vida: inclusão social de usuários de um Centro de Atenção Psicossocial na vida cotidiana.

12. Santos JC. O estigma da doença mental: compreensão e ações dos trabalhadores dos CAPS [dissertação]. São Paulo: Universidade de São Paulo; 2013.

13. Braga FS, Olschowsky A. Pleasure and suffering in the work of mental health nurses in the contexto of the psychiatric reform. Rev enferm UFPE online [Internet]. 2015 [acesso em 2016 Abr 26];9(3):7086-94. Disponível em:

http: / /www.revista.ufpe.br/revistaen fermagem/index.php/revista/article/ view/6295/pdf_7391

14. Guimarães GTD. Aspectos da teoria do cotidiano: Agnes Heller em perspectiva. $1^{\text {a }}$ ed. Porto Alegre: EDIPUCRS; 2002.

15. Rinaldi DL. Micropolítica do desejo: a clínica do sujeito na instituição de saúde mental. Cienc saude colet [Internet]. 2015 [acesso em 2017 maio 16];20(2):315-23. Disponível em: http: / /www.scielosp.org/scielo.php?s cript=sci_arttext\&pid=S1413$81232015000200315 \& \operatorname{lng}=e n$

16. Thornicroft G, Tansella M. Boas práticas em saúde mental comunitária. $1^{\mathrm{a}}$ ed. Barueri: Manole; 2010.

17. Tsemberis $\mathrm{S}$, Eisenberg RF. Pathways to housing: Supported housing for street-dwelling homeless individuals with psychiatric disabilities. Psychiatr serv. 2014;51:487-93.

18. Souza MCMR. Representações de profissionais da saúde mental sobre sexualidade de pessoas com transtornos mentais [tese]. Belo Horizonte: Universidade Federal de Minas Gerais; 2014.

19. Cortes JM, Kantorski LP, Barros S, Antonacci MH, Magni CT, Guedes A. O laço social de indivíduos em sofrimento psíquico: contribuições para a enfermagem psiquiátrica. Rev enferm UFPE online [Internet]. 2015 abr[acesso em 2016 maio 28];9(4):7322-9. Disponível em: http://www. revista.ufpe.br/revistaen 


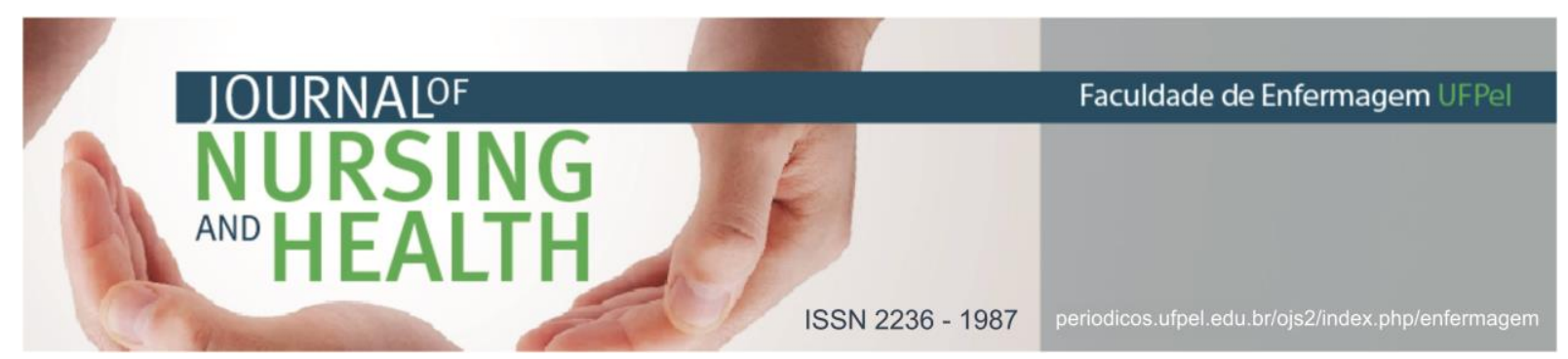

fermagem/index.php/revista/article/ view/7343

20. Kantorki LP, Cortes JM, da Cruz Guedes A, Franchini B, de Aquino Demarco D. O cotidiano e o viver no Serviço Residencial Terapêutico. Rev eletrônica enferm [Internet]. 2014 out/dez [acesso em 2016 maio 28];16(4):759-68. Disponiavel em: http://dx.doi.org/10.5216/ree.v16i4. 22923

21. Aranha e Silva AL. A construção de um projeto de extensão universitária no contexto das políticas públicas: Saúde Mental e Economia Solidária [Livre docência]. São Paulo: Universidade de São Paulo; 2012.

22. Barone R, Bruschetta S, D’Alema M. L'inclusione sociale e lavorativa in salute mentale. Milano: FrancoAngeli; 2013.

Data de submissão: 15/10/2016

Data de aceite: 28/05/2017

Data de publicação: 30/08/2017 